\title{
Getting the write message right: Review of guidelines for producing readable print agricultural information materials
}

\author{
Craig D Morris' and Christine Stilwell ${ }^{2}$ \\ Information Studies, School of Human and Social Studies \\ University of Natal, Private Bag X01, Scottsville 3209, Pietermaritzburg, South Africa \\ morris@nu.ac.za
}

\begin{abstract}
Print agricultural information materials (PAIMs), such as leaflets, booklets and fact sheets, are used extensively to provide information to farmers. Such print materials can play a vital supportive role in extension, even to low-literate communities. Principles for repackaging technical and scientific agricultural information in print are reviewed to provide guidelines for producing PAIMs that are 'considerate' of the target audience's information needs, communication and language style, and level of reading and education. Criteria for choice of content include brevity, accuracy, appropriateness and relevance to the end user. An understanding of factors affecting readability, accompanied by readability assessment and pretesting materials on users, will ensure greater clarity of expression and aid comprehension. Important elements of the design and layout of PAIMs include logical organisation of content and arrangement of text on the page, legibility of the text as affected by colour and typography, highlighting, and the use of pictures to complement and reinforce the message. Such design tools should be used to attract and not distract the reader. It is concluded that a collaborative effort of communicators and audience in the development process will aid the production of PAIMs that contribute effectively to the diffusion of agricultural and development information in rural areas.
\end{abstract}

\section{Introduction}

Scientific and technical information is important in both subsistence and commercial agricultural production systems (Youdeowei et al. 1995). Information is critical for farmers to maintain livelihoods or to gain a competitive edge in a rapidly changing economic and production environment where traditional farming methods might be insufficient to meet new demands (Morton \& Matthewman 1996). Extension agencies frequently produce printed agricultural information materials (PAIMs), such as brochures, leaflets, booklets and newsletters, to disseminate information to farmers (Velasco et al. 1996). Morris (2000) identified I 38 such PAIMS produced in South Africa to provide information to communal livestock farmers or their advisors.

The purpose of producing a PAIM would be to present, in an attractive and readable form, technical information that the intended user requires for his/her farming. To achieve this, scientific and technical agricultural information needs to be consolidated, rewritten and appropriately packaged. Stilwell (2000) noted the importance of such 'repackaging' of information for rural dwellers in developing countries where the 'information divide' between the information-rich (usually urban) and information-poor (the rural poor) (Castells 1996) is not only wide but also deep because of a dearth of information in a readable and useable form. Sturges and Neill (1998:44) suggest that repackaging should be a priority of government and other extension/information agencies because "information that the extension workers are supposed to disseminate too frequently takes the form of a series of highly technical packages, which are no doubt as incomprehensible to them as they are to the barely literate farmers they are struggling to advise."

Bembridge (1997) surveyed the availability of printed extension material aimed at small-scale farmers in South Africa and found the quality of available publications to be variable and their distribution ad hoc. Few objective criteria have been consistently applied to evaluate the quality of information materials (Bembridge 1991). Guidelines are therefore needed to assist extension communicators working in academic, government, parastatal and non-government organizations develop effective print extension materials and to evaluate existing PAIMs for possible use in the communities they serve.

This review addresses the critical gap in the knowledge concerning guidelines for the production of readable and useful print extension materials. Literature relevant to the topic is fragmented and dispersed, largely available as tips on specific aspects of repackaging rather than as an integrated set of guidelines for extension communicators. Little of the available material is aimed at repackaging agricultural or other rural development information.

Our primary purpose is to review and consolidate the agricultural as well as health/nutrition and basic adult education literature on repackaging extension information in print. Before reviewing best practice for producing PAIMS, the role of print in disseminating agricultural information is briefly discussed to clarify the advantages and disadvantages of this medium for information exchange. We review procedures for evaluating the quality of PAIMs elsewhere (Morris \&

I. Present address: CD Morris. Agricultural Research Council - Range and Forage Institute, c/o University of Natal, Private Bag X0 I, Scottsville 3209, Pietermaritzburg, South Africa. E-mail: morris@nu.ac.za

2. Professor C Stilwell. School of Human and Social Studies, University of Natal, Private Bag X0I, Scottsville 3209, Pietermaritzburg, South Africa. E-mail: stilwell@nu.ac.za 
Stilwell in prep.). The review is limited to information repackaged in print, specifically information brochures and pamphlets, and does not address repackaging principles for other print forms (such as newspapers or books) or media (audiovisual, theatre, radio) where different design principles may apply. The multifaceted (and contextual) nature of the term 'information' is recognized (Poole 1985) but for the purposes of this review information will be defined simply as "data of value in decision making" (Saracevic \& Wood 1981:12) to emphasise that information has no value [to farmers] if it is not eventually used to assist in making a decision.

\section{The role of print in agricultural information exchange}

Print is still the primary medium whereby agricultural information is recorded, stored and transmitted, despite inroads made by electronic media (television, internet) (Velasco et al. 1996). Types of print materials used in extension, and the advantages and disadvantages of using print to disseminate agricultural and development information to illiterate or lowliterate farmers in developing countries are briefly discussed so that producers of such materials may have a realistic understanding of their potential to convey a message.

A wide variety of PAIMs are used in agricultural extension including hand-written notices, information and news bulletins, newsletters, newspapers, posters, cartoons, folders, leaflets, pamphlets, fact sheets, manuals, booklets, training manuals and books (Behrens \& Evans 1984; Bembridge 1991). The scope and brevity of such materials vary from single page leaflets containing brief facts about a particular subject to extensive treatment of a subject or a series of related topics in books or training manuals. PAIMs can be categorized into three broad types according to their primary purpose: (1) to broadcast news or notices of relevant agricultural and development activities, (2) to disseminate information on agricultural technology and farming methodology, and (3) to support farmer education and training programmes. PAIMs may also be multipurpose, where, for example farmer newspapers present news material as well as advice relevant to farmers.

Advantages of print

Print has inherent attractive qualities that make it a suitable medium for information diffusion in rural areas. PAIMs are easily transported from place to place so that "the message can be received in virtually any physical situation" (Stewart 1985: 14I). Print messages require relatively simple and cheap technology to produce (relative to audio and visual media) and no equipment to transmit and decode the information content (Sturges \& Neill 1998). Print can be used as many times as the user requires, to quickly look up some fact or to study its contents in-depth, and is easily stored for future reference (Bembridge 1997). Carter (1999:8) relates a striking example of the value of print materials as a handy reference source (in rural environments where PAIMs are generally scarce) through her observation of how a farmer in western Kenya treasured his notes from agricultural training undergone twenty years previously, which he regularly consulted (as his only written source of information) to answer fellow farmers' questions on row spacing, pest protection, and so on. A further advantage of print is that it is allows for greater accuracy of content and precision of expression than media where the message depends on oral transmission and the receiver's memory (Stewart 1985). However, print does not allow for immediate feedback should the user not understand the content. Farmers might therefore need to seek explanations from fellow farmers or from extension advisers to clarify certain aspects of the printed message (Leach 1999).

\section{Disadvantages of print}

Despite its advantages, many communication and extension specialists have argued against print as a medium for disseminating information to farmers in developing countries, principally because of two shortcomings of print messages. First, text messages are seen as irrelevant to a largely illiterate rural society that relies on and prefers verbal communication (Aboyade 1987; Leach 200I). Second, the print media is viewed by some (for example, Ozowa 1995; Avgerou 2000) as inextricably linked to outmoded models of communication and extension, the 'transmission of information' (sensu Shannon \& Weaver 1949) and 'transfer of technology' (ToT) models respectively. The ToT extension approach, also widely termed the 'diffusion of innovations' model, involves mainly a one-way flow of knowledge from the information producers (research scientists), through the extension service, to the farmer (Rogers 1983). The text message, it is therefore argued, represents, at its worst, the dictatorial, non-consultative extension paradigm of informing the 'ignorant' rural farmer how and what s/he should farm.

Print as a prescriptive message

A prescriptive style of communication is, however, not an inherent characteristic of the print medium. Print information materials can be developed with audience participation at all stages of the materials development process. It is generally recognized that information interventions should always start by allowing the target audience (the community) to articulate its information needs (Hewins 1990; Kaniki 200I). Choice of content should also be a consultative rather than a 
top-down process. Various parties in the agricultural information system (farmers, advisers, researchers) can use print to share rather than to impose ideas. For example, Carter (1999) reported significant farmer-to-farmer sharing through locally generated print materials in rural regions of Ghana and Uganda. Many (for instance, Richardson 1996; Carter 1999; Munyua 2000; Stilwell 200I) have also noted the importance of including local content, preferably rich with local examples and recognisable illustrations, in print as well as other extension materials, including those delivered electronically. Indigenous (common) knowledge can be powerfully fused with exogenous (scientific) information to produce synergistic knowledge (sensu Karlsson 1995) that can be recorded and presented in print materials for local and broader circulation.

Traditional oral media (folk tales, drama) and direct face-to-face contact are probably more effective than print messages for information sharing because they allow conversation, debate and immediate feedback relatively unimpeded by cultural and technical barriers to communication (Burton 200I; Stilwell 200I). Some principles for repackaging information for traditional media have been outlined (Rosenberg 1987).

Information diffusion through direct contract is, however, more costly in time and effort than broadcasting by mass media such as print, radio and television. Internet-based information communication technologies (ICTs), especially electronic mail and the World Wide Web (the Web), also have potential to support and extend oral and print communication by providing an efficient, dynamic, multi-media platform for delivering agricultural information right to the doorsteps of rural dwellers, or at least to community information centers (telecentres) (Munyua 2000; Kiplangat 200I) the 'Information Village' experiment in Chennai, India is an encouraging example of how locale-specific (repackaged in the vernacular) information can delivered electronically (Arunachalam 1999). Initial enthusiasm for these ICTs has, however, been tempered by a realistic understanding of the potential social impact (Castells 1999) and limitations of electronic communication in rural regions with severely limited telecommunications infrastructure (Lush \& Rushwaya 2000; Jensen 2002). What is also largely unknown is how best to write and present content on Web pages (Graber et al. 1999) in a way that is simple to access, view and comprehend by users who are as yet largely unfamiliar with this medium. Research is needed to investigate how print materials can be repackaged to make the best use of the multimedia features of the Web to deliver agricultural and development information.

The illiteracy barrier

The more obvious obstacle to effective use of PAIMs in extension is the high level of illiteracy among rural inhabitants'. Noting problems of information dissemination to small farmers in Africa, Ozowa (1995:7) contends that "The print media which includes leaflets and newsletters as message carriers are of limited use in reaching illiterate farmers." Correa et al. (1997:7) conclude: "When high rates of illiteracy are present, print-based systems are definitely unsuitable" (emphasis added). Other studies concur that illiteracy is a significant barrier to reaching many farmers in preliterate rural societies and that the print medium is therefore inappropriate for information sharing in developing areas (Aboyade 1987; Aina 1990; Melkote 1991; Kularatne 1997; Mansell \& Wehn 1998).

The barrier of illiteracy to the effective use of print materials in rural areas may, however, be more perceived than real because illiterate individuals can usually find a functionally literate family or community member to read to them (Sturges \& Chimseu 1996; Bembridge 1997; Carter 1999). Carter (1999:79) emphasises that, what she calls 'group literacy' or family literacy is probably more important than the literate ability of individuals. A group (of farmers or community members, for instance) needs to have only one [willing] literate member or even sympathetic non-member to be able to access information in books, newspapers and other PAIMs. Increasing penetration, and consequent use of print materials, can also be expected as the absolute rate of individual literacy rises in rural areas (Sturges \& Neill 1998). The permeability of the illiteracy barrier is reflected in ownership and use patterns of texts in semi-literate societies. Amaratunga and Shute (1982:564) reported that in Ghanaian villages: "Almost every house which the interviewers visited had a few books or magazines." More recent studies in Ghana and Uganda confirmed the value of print materials for semi-literate and illiterate farmers (Carter 1999). Almost one-third of the farmers interviewed included printed information in their top five most trusted sources of agricultural information, and individual farmers and especially farmer groups and associations actively sought printed information that provided practical and relevant agricultural or livelihood advice. Such materials were circulated among group members and their contents actively debated and discussed at group meetings to evaluate the local applicability of the proffered advice (Carter 1999).

In summary, the literature suggests a growing realisation of the critical supportive role that print information materials can play in extension communication strategies that employ a mix of media and messages tailored to the target community in their context. Print supports messages delivered orally just as verbal communication expounds and

I. Defining and measuring literacy rates is problematic. Bembridge (1995) estimated that $50-60 \%$ of rural inhabitants in South Africa were illiterate and that most were functionally literate only in the vernacular. 
explains, and is often stimulated by, print materials. Crucially, print materials provide a vital reference source for farmers to consult when the details of the 'talk' have faded from their memory.

\section{What to write - choosing content}

The choice of what content to present in a PAIM should be firmly grounded on an understanding of the information needs of the intended audience, that is, on a specific expressed information need rather than on what the author of the PAIM thinks the audience should know. The well-researched arena of information needs assessment has been discussed by Hewins (1990), Anyaegbunam et al. (1999) and Kaniki (2001). These studies emphasise that a high degree of audience participation in the evaluation process will increase the chance that the content of the PAIM(s) will be relevant to their needs. In practice, however, choice of content, style and layout of print and other extension materials is often done by an individual or a team of scientists and/or communication specialists (but see examples of secondary community repackaging described in Carter 1999). This section consolidates guidelines available for choosing appropriate content, including considerations on depth and length, thematic complexity, accuracy, appropriateness and relevance of the message to the target audience.

\section{What to include?}

Choosing appropriate content starts with searching for and perusing primary and secondary sources, including personal experience and local (indigenous) knowledge (Ballantyne 2002), to identify information that might be relevant to the topic of the PAIM. Velasco et al. (1996:37) note that "Content has to be selected through a systematic, disciplined approach, starting by attempting to match content to the aims and objectives of the material as dictated by the target group's needs." Selection of material is followed by a process of information consolidation during which a number of analytical and synthetic activities might be employed, such as evaluating materials as to their intrinsic merit and validity, analysis to extract salient and relevant features, and restructuring of information by merging, synthesis and review (Saracevic \& Wood (98I).

Saracevic and Wood (1981) argue that information consolidation adds value by reducing the amount of information that decision-makers and problem-solvers (that is, the farmers) have to consult to assist their decision making. Following this logic, information that is presented as a concise set of unambiguous recommendations (underpinned by logical explanation), expressed in a familiar style and language will be most valuable to the end user. Conversely, unconsolidated, technically complex information dispersed across sundry sources is of little value to most information seekers. PAIMs therefore largely fall within the realm of brief, highly consolidated information packages that are of greatest potential value to farmers.

How long should the message be?

Brevity is a key principle in information repackaging (Bembridge 1997). Physical form does usefully limit the volume of information that can be presented in a pamphlet, brochure or fact sheet ' (Behrens \& Evans 1984). Nonetheless, the tendency of scientists is to include too much irrelevant information in information materials (Turk \& Kirkman 1989:5). As Glanz and Rudd (1990:114) suggest, "Excess length may make the brochure or pamphlet seem overwhelming to the intended user, or might inhibit complete reading of the information."

Content should include only what the reader absolutely needs to know about a particular topic and should be as short and simple as possible without losing meaning (Bembridge 1991). By asking the question "Does the reader need this fact or statement to take the desired action?" the writer can eliminate information that might be interesting but not crucial to the reader's needs ( $\mathrm{NCl}$ 1994). Information should be prioritised and superfluous information identified and ruthlessly culled at the start of the writing process (Velasco et al. 1996).

The volume of content is affected by the thematic complexity of the subject. Bembridge (199|) recommends limiting each pamphlet/leaflet to one major theme only (to maintain a low concept density). If the subject has a number of facets that need to be presented together for coherence then the number of sub-themes included should be limited to "an appropriate number of concepts for the length of the piece" (Betterley et al. 2000:2). Presumably, this requires sacrificing detail on each aspect of the subject to provide a more superficial overview of all the important elements of the subject.

How technical should the message be?

The aim of repackaging is to present the content of a message in as comprehensible a manner as possible (Stilwell 200 I). To achieve this, the essential technical details of a subject have to be explained in simple terms for the reader. However, in paring away the details of a subject the writer of the PAIM should take care not to distort the scientific and technical

I. The median length of farmer information leaflets in South Africa is two pages (single sheet) with few exceeding four pages (double sheet) in length (Morris 2000). 
facts ( $\mathrm{NCl}$ 1994). The content should always be accurate and credible as well as appropriate and relevant to the intended user. These aspects of content are elaborated below.

\section{Accuracy}

To convey a credible message, information presented in a PAIM should be factually correct, evidence-based and current (Smith 1998). Betterley et al. (2000:3) list some questions writers or reviewers of information materials should ask with respect to accuracy:

I. Is the information based on up-to-date and credible research?

2. Are references and resources accurate and up-to-date?

3. Is the author or producer of the materials a credible source?

Inaccuracies can be eliminated by carefully checking and validating facts and through a process of peer consultation and review (Bembridge 1991). To ensure that information presented in a PAIM is 'state-of-the-art', content may need to be reviewed regularly and either revised or replaced by updated information (Salmon \& Myers 1999). Out-of-date materials should be removed from circulation to maintain the credibility of the extension message (ibid).

\section{Appropriateness}

The obvious question when choosing the content of a PAIM is whether the information is "appropriate for the target audience" (Betterley 2000:2). Thorough understanding of the social context and community characteristics will assist in developing content that is "culturally and linguistically appropriate" (Smith 1998). Specifically, information should be appropriate to the "age, gender, educational level, ethnicity, socioeconomic status and lifestyle of the target audience" (Betterley et al. 2000:3). It is critical that information materials should be made available in other languages for readers not proficient in the official language (Smith 1998) but few of the locally produced PAIMs have been translated from English or Afrikaans into the main, let alone the minority, languages of South Africa (Morris 2000). However, Carter (1999) stresses that information materials should not just be simply translated verbatim but rather rewritten in a language and style appropriate to the specific cultural group or community.

\section{Relevance}

Central to the criterion of relevance is whether the information: "... addresses the target audience needs and concerns" (Betterley 2000:2). Comprehensive assessment of information needs can contribute toward the choice of relevant and useful content, but the end user is in the best position to decide whether an information product successfully meets his or her need. Feedback from users is essential to ensure relevance.

If the information presented reflects the needs and interests of readers then they will be motivated to consider whether they could apply the given guidelines and recommendations in their own particular situation. The user should be able to see how s/he could benefit from the information (Bembridge 1991). Use of real life examples, preferably in a familiar context, to reinforce any general or abstract ideas will help attract the reader's attention and inspire confidence to apply the ideas in practice (Anderson et al. 1980; $\mathrm{NCl}$ 1994).

In a survey of PAIMs produced for the small-scale farmer in South Africa, Bembridge (1997) found that the content of these extension materials was mostly just prescriptive, instructing the user what to do rather than how and why it should be done. Actions or behavioural changes required to successfully implement the technology or management recommendations should therefore be clearly outlined (Betterley et al. 2000). In summary, information will be relevant to the user if it is "essential, immediately applicable [and] actionable with a focus on desirable behaviour and action rather than facts" (Smith 1998).

\section{How to write - readability and comprehension}

If the content chosen for the PAIM is appropriate to the user's situation but the language in which it is written is complex and terminology used obtuse, then the reader will not be able to read, comprehend and ultimately make use of the information. It is important, therefore, to understand the factors that contribute to ensuring that the message can be easily read and understood. Accordingly, in this section readability is defined, its elements noted, and criteria commonly used to measure readability are briefly outlined with some recommendations for their use in developing readable PAIMs. Other factors, apart from the grammatical and syntactic construction of the text, that affect comprehension of print information are discussed.

How readable are PAIMs?

"Almost every extension service over-estimates the ability of its audience to read a printed message and understand it clearly" (Behrens \& Evans 1984:147). This assertion is supported by evidence from numerous studies in the agricultural, health, nutrition and business sectors examining the readability of print education materials (for example, Leichter et al. 
1981; Burton 1991; Johnson \& Verma 1992; Estey et al. 1994; Kingbell \& Speece 1995; Dollahite et al. 1996; Chung et al. 2000; Singh 2000). Such studies concluded that the written information materials provided for clients or patients would not be easily read and understood by their intended users because of the complex content, and, more importantly, the abstruse wording and writing style of the message. For example, Glanz and Rudd (1994:114) reported that their assessment of print cholesterol information materials "suggests that the majority [of materials] are aimed at welleducated, middle class, middle-aged, non-minority populations who are highly motivated to translate abstract contents ..." Others with less education and poorer literacy skill would consequently struggle to read and understand the message conveyed by these materials. Higher tertiary education seems to retard the ability of agricultural extensionists to produce readable PAIMs, perhaps because capabilities to deal with abstract and complex subjects acquired at a high level degrade their ability to think and write simply (Johnson \& Verma 1992). Extension communicators should therefore give careful attention to factors that reduce the readability of their PAIMs.

What is readability?

Readability has been defined in various ways. Salinas (1988, cited by Velasco et al. 1996) suggested that readability has a lot to do with writing in a simple, clear and concise way. McLaughlin (1969:639) brings the reader into the equation by defining readability as "the degree to which a given class of people find certain reading materials compelling and comprehensible", whereas Burton (199l:I) focuses on the interaction between reader and the text: "Readability is concerned with the degree to which the reader can share meaning with the writer." The classic definition of readability is that of Dale and Chall (1948:I I):

readability is the sum total (including interactions) of all the elements within a given piece of printed material that affect the success which a group of readers have with it. The success is the extent to which they understand it, read it at optimum speed and find it interesting.

This definition suggests that various related components of content, layout, style and structure of the text affect the readability of information materials. It also highlights the three principal aspects of readability, namely comprehension, fluency (of reading) and interest. These three elements are not independent as, for example, reading speed and the motivation to read further might be retarded if the material is difficult to comprehend. Similarly, a reader might not understand the content of the material, and lose interest in trying to do so, if the message is written in a complex style. Assessing the readability of print materials before their dissemination is one way of reducing impediments to reading and comprehension.

What criteria can be used to assess readability?

Readability has been subject to extensive quantitative assessment through readability testing which "examines the linguistic and structural qualities of written content" (Glanz \& Rudd 1990:110) by calculating one or more readability measures of the difficulty of the vocabulary and sentence structure. Readability formulas predict the level of reading ability required to read a particular text in terms of Reading Grade Level (RGL) or education grade-level (number of I0-month instructional years) (Burton 1991). Specialists in health information and education suggest that writers should aim for a readability level of no higher than the sixth-grade (Estey et al. 1994; Doak et al. 1996), and perhaps as low as the thirdgrade level ( $\mathrm{NCl}$ 1994; Dollahite et al. 1996), to ensure that their information materials are readable by those with low literacy skills.

More than thirty different formulas for calculating readability have been developed by educators and publishers since the 1940s (Kingbell \& Speece 1995). Those more commonly used include Dale and Chall (1948), Flesch (1948), Fog (Gunning 1952), Fry (1968) and SMOG (Simple Measure Of Gobbledygook; McLaughlin 1969). Most readability formulas are based on two measures, that is the number of polysyllabic words ( $>=3$ syllables) and the average number of words per sentence (Meade \& Smith 1991; Nitzke \& Voichick 1992), on the assumption that monosyllabic words and short sentences are easier to read than complex sentences with a high proportion of polysyllabic ('big') words. Formulas vary from simple hand-calculated indices (SMOG, Fry) to complex formulae calculated by dedicated readability software (RightWriter, Sensible Grammar; Liptak 199I) or modern Word processor software packages' (for instance, Flesch Reading Ease and Flesh-Kincaid formulas in MS Word and WordPerfect). SMOG, which is based on the number of polysyllabic words in a sample of 30 sentences from the text (and calculated as the square root of this number +3 ) has been widely used to assess medical and nutritional print materials because it is simple, quick to calculate and provides accurate and consistent scores (Glanz \& Rudd 1990; Meade \& Smith 1991; NCl 1994).

I. Computer-based calculations of readability might overestimate the number of sentences if periods within abbreviations are automatically counted (Nitzke \& Voichick 1992). 
A comprehensive evaluation of the various readability formulas is beyond the scope of this review. Rather, some advantages and drawbacks of readability formulas in general and their usefulness for guiding writers of print extension materials are briefly discussed below.

How useful are readability formulas?

Readability formulas are popular because they are "relatively easy to employ, they give quantitative ratings, and they help writers use simple sentences and vocabulary" (Nitzke \& Voichick 1992:263). The scores calculated by different formulas are precise (within 1.5 standard deviations for SMOG) and generally highly correlated with one another for the same piece of text (Glanz \& Rudd 1990; Meade \& Smith 1991; Kingbell \& Speece 1995). However, indices do differ in their emphasis (and hence interpretation) and mean scores have been demonstrated to differ significantly among formulas despite being positively correlated (Kingbell \& Speece 1995). Multiple formulas should therefore be employed to assess a text (Leichter et al. 198I) and an average readability index calculated across all scores (Kingbell \& Speece 1995). Further, readability of the most difficult section of the document, which could inhibit further reading, should also be calculated along with the average overall readability of the text (ibid).

Meade and Smith (1991:155) warn that the power and precision of readability indices may "give a false sense of the validity of the process of assigning grade level equivalencies to text ... [and] ... cause one to overlook the other important factors associated with being able to read." The fundamental assumption that text comprised of short and simple sentences is most easy to read and understand has been challenged on two fronts. First, long (polysyllabic) words might be easy to read if they are in common parlance and are familiar to the reader ('television' is one such example). Conversely, short, jargon words might impede reading and comprehension. Most importantly, authors of PAIMs should "Write the way you talk" (Bembridge 1991:24) by employing a personal, conversational, respectful and friendly style.

The second, perhaps more serious criticism of the underlying tenets of readability formulas is that "the practice of using simpler words and shorter sentences is unlikely to enhance readability ... because it does not take into account the numerous other text variables that are known to affect comprehension" (Singh 2000:216). Some text variables known to facilitate comprehension include: (I) integration of high level ideas across the whole text (global coherence) and within and between sentences (local coherence), (2) unity of purpose and relevance of the information, (3) appropriateness of the vocabulary for the target audience, (4) the use of adjunct questions to test the reader's understanding, and (5) stylistic (for instance, passive not active voice), typographic and pictorial features (Singh 2000). Singh (1994) uses 14 such variables or sub-variables in her comprehensive Readability Assessment Instrument Manual (RAIN) to produce text which is "considerate" to the reader (Singh 2000:216).

Orna's (1995) view is that readability is not inherent in text but depends on the interaction between text and readers. Cultural and experiential factors as well as the "conceptual background" of the reader (Meade \& Smith 1991:156) influence the extent to which a reader is able to decode and derive appropriate meaning from a particular text. Nitzke and Voichick (1992:264) argue that reading requires a "close correspondence between the receptive languaging ability of the reader and the expressive language of the author ... [that is to ensure] a match between the text and the reader's schema (knowledge/background)." The extent to which a reader can understand figurative language, symbolism and connotations in the text is not measured by readability formulas (Arthur 1995) and can only (and should always) be verified by testing the comprehensibility of the text on readers (Orna 1995). Involving the intended audience in the production of the 'message' is one way through which the more elusive, audience-determined influences on readability and comprehension can be considered. An example is the Language Experience Approach (LEA) which uses personal oral statements obtained from the target audience through group discussion to tap, record and incorporate into text, the oral expressions, thinking processes, mental associations and language patterns of intended users of print education materials (Nitzke \& Voichick 1992).

Also largely unknown is the usefulness of readability measures for predicting the reading ability of neo-literates especially those reading in a second or third language. Caution should also be exercised when applying readability formulas to an audience different to that on which the formula was validated (for instance, children in the USA for SMOG; Kingbell \& Speece 1995) ( NCl 1994). Assessing the readability of print materials repackaged for rural dwellers in developing countries may therefore require novel methodology and assessment criteria.

To summarise: readability calculations can be used by writers of PAIMs to obtain an initial assessment of readability and to highlight potential syntactic and semantic obstacles to reading. However, extension writers should be aware of the complex and interactive nature of reading and comprehension and the numerous textural and human factors that determine whether a particular reader will be able to read, understand and usefully apply the message conveyed by a PAIM. Human judgment and common sense, rather than just mechanised analysis, are important when writing and assessing information materials (Burton 199I; Meade \& Smith 199I). 


\section{How to present the message - design and layout}

Writers of information materials should invest in designing the appearance of PAIMs to attract and keep the reader's attention. Research indicates that users respond to design features that increase the attractiveness of information materials (Frost et al. 1999). We consider the following important and interrelated elements of layout and design of a PAIM: (I) organisation of content, (2) layout of the text on the page, (3) legibility of the text as affected by colour and typography, and briefly (4) the use of pictures and other graphics to complement and reinforce the message. These elements contribute to the overall appearance of the PAIM but are also integral components of readability as they contribute to making the words more meaningful and interesting to the reader (Velasco et al. 1996).

How should the message be organised?

The information "has to be presented in a way not only convenient for the readers but interesting and motivating as well" (Velasco et al. 1996:38). This requires a logical arrangement of content.

Both Bembridge (1991) and Velasco et al. (1996) point out the natural geometry of readership and reading attention: information presented at or near the beginning of any document tends to attract the most readers and be perused more thoroughly than information presented in the middle and especially at the end of the document. Accordingly, Bembridge (I99I) recommends that the most important facts or key points be presented first but reiterated, perhaps in another form, in the tail of the document so that the most important point(s) of the message are the first and last things to be read.

Content should be broken up into 'digestible' paragraphs or bulleted points limited to a single message and arranged so that ideas flow smoothly and logically (Betterley et al. 2000). For example, information may be ordered either by recommended actions (for example, steps I, 2, 3...), by topic (main and sub-themes) or by time (of day, season) that the action should be undertaken ( $\mathrm{NCl}$ 1994). Usually, general information should precede specific information for a particular crop, locality, farming system, time-of-year, and so on.

Repetition, revision, and summary are organisational tools that can be used to draw attention to the key points of the message (Smith 1998) and to enhance their comprehension and retention (Anderson et al. 1980). The title is the first point of summary and should prominently indicate the central theme or purpose of the document in as precise and concise a manner as possible (Bembridge 1991). Titles such as "Are my pigs sick?" or "How to grow cabbages" clearly indicate what the reader can expect to learn by reading the article. Even if the purpose of the document is apparent from the title, it is good practice to unambiguously outline at the beginning of the article the purpose or objective(s) of the information material (why it was written) and what the reader might expect to learn from reading the document (Betterley 2000). For example, an opening statement like "This leaflet provides a guide on how to use lime fertilizer to grow more and bigger mangoes" clearly indicates what the article is about and how the reader could benefit by applying its recommendations.

A short statement of content (for example, "Diagnosis, treatment and management of poultry are discussed in this information brochure"), or for longer documents a table of contents, at the beginning of the document provides the reader with a guide to the overall structure of the article and its scope (Velasco et al. 1996). Advance organisers (headers) help readers locate information quickly $(\mathrm{NCl}$ 1994). The source(s) of the information presented in the document and the author of the information package and his/her official affiliations and contact details should be presented at the end of the document. This will aid credibility (Betterley et al. 2000) and allow the user to contact someone should explanations be required. Additional related information materials (readings, slide shows, videos) can be listed at the end of the text to take the reader further.

After selecting and organising its contents the author of a PAIM should ask: "Does the overall organisation of the key concepts contribute to [the reader's] understanding?" (Betterley 2000:2).

What is the best layout for the PAIM?

Layout is "the arrangement of the elements of the material on the page" (Velasco et al. 1996:40) and includes choice of cover, use of white space and margins, and variation in line length and text justification. These tools should be used to good effect in a PAIM to attract and capture the reader's attention so that he or she will want to pick it up and read it because they find it "attractive, colourful and impelling" (Behrens \& Evans 1984:147). The arrangement of items in a PAIM is also important because "very simple displays (text heavy, isolated graphics) can be boring to readers, while very complex displays (busy, lack direction for the reader) can be confusing" (Boone 1996:5).

A professional look to the front cover or first page, and indeed the whole document, is necessary to convey to the reader a sense of overall quality and importance of the material within (Smith 1998). The cover or front page has a different function to the rest of the document (Behrens \& Evans 1984). Primarily it should make the purpose of the 
document immediately clear to the viewer (who hopefully becomes the reader) and it should create the all-important favourable first impression. Graphics and pictures are frequently used on the frontispiece to attract attention.

The text and visual material within the rest of the document can be arranged on the page(s) to maximise the legibility of the text. Legibility, in this sense, refers to how easily letters and words can be recognised (Meade \& Smith 1991). Crowding of words in long paragraphs with insufficient space between blocks of text intimidates the reader and reduces the legibility of the text (Coey 1996; Betterley 2000). 'White space', defined as "a space of two or more lines between blocks of text" (Glanz \& Rudd 1990:III), is a useful tool for separating text ('black space'), graphics, and text from pictures. It allows 'breathing room' for the pages, making full and 'heavy' pages lighter, and allowing items (such as pictures, headlines) to emerge from the text when surrounded by white space (Velasco et al. 1996:40). Care should, however, be taken to keep related element, such as titles, subtitles and allied text, relatively close to each other to unambiguously indicate their affiliations ( $\mathrm{NCl}$ 1994).

In text designed for continuous reading, it is recommended that the length of lines should be restricted to between 50-70 characters (Boag 1992, cited by Velasco et al. 1996; RNIB 2000). Margins and line length can, however, be adjusted to suit the reader; increasing the margins and hence reducing line length for visually impaired readers or those with a low reading ability (Saracevic \& Wood 1981; RNIB 2000). Writers should avoid confusing such readers by splitting words at the end of lines (RNIB 2000). Line-length, type-size and letter and word spacing are interrelated. A simple rule provided by Boag (1992; cited by Velasco et al. 1996) for optimising spacing is that the space between letters should be less than word space, and word space less than the space between lines.

It is generally recommended that text be left rather than fully justified (Velasco et al. 1996; Parker 1997; Betterley 2000; RNIB 2000) because variation in spacing between words in fully justified text could make text more difficult to read (Payne et al. 2000). The negative effects of full justification are especially marked for text within narrow columns or adjacent to graphic or text boxes (Velasco et al. 1996; Parker 1997).

How should colour be used?

Colour can be used to enhance the attractiveness of information materials and for highlighting important text (Anon. 2000). Generally, extension materials are more appealing to the reader when some colour is used rather than just black and white (Behrens \& Evans 1984). Two aspects of colour to consider are the colour of the paper (background colour) and the colour of the print (type).

Coloured paper can provide an attractive backdrop to the message. Paper colour should be muted rather than bright to avoid reducing the legibility of the text $(\mathrm{NCl}$ 199). Mat (non-gloss) paper reduces glare and enhances legibility (Culbertson et al. 1988, cited by Arthur 1995) and is recommended by the Royal National Institute for the Blind (RNIB) as a standard for all readers, not only those with a visual impairment (RNIB 2000). In addition, good quality paper should preferably be used (ibid), that is paper of sufficient density to render print invisible from one side of the page to the other (Betterley et al. 2000). It is also critical to ensure a good contrast between the colour of the paper and that of the print so that the print is legible (Nitzke \& Voichick 1992). Recommendations on what colour combinations to use and which ones to avoid are available (see NCl 1994; Velasco et al. 1996; RNIB 2000).

Within the above constraints, colour can be chosen to appropriately reflect the contents of the message, for instance, dark green for pasture-related topics, dark brown for information on soils, and so on (Behrens \& Evans 1994). People's preference is idiosyncratic so it is recommended that the chosen colour scheme be pretested on the intended audience if possible ( $\mathrm{NCl}$ 1994). Practically, the use of colour will be determined by the available budget for printing. It is suggested that the expense of colour might not be warranted for print runs of fewer than 1000 (Anon. 2000).

In conclusion, colour should be used carefully so as to enhance and not detract (and distract) from the overall presentation of the message (Betterley 2000).

What typeface to use?

Legibility is strongly influenced by typography (RNIB 2000). Of the three type-related elements of typography (typeface, size and weight), choice of typeface (font type) is perhaps less important than choosing an appropriate font size and weight as most of the less fancy typefaces available via a word processor are easy to read (RNIB 2000). However, Velasco et al. (1996, citing Cooper 1994) suggest that fonts with serifs (for example, Times Roman, Bookman) should be used for most of the text as they are easier to read than sans serif fonts. Sans serif fonts (for example, Arial, Verdana) could be for short sections of the text that may need to be highlighted or stand-alone (such as headings, captions) (ibid). Distinct fonts are preferable to light, spindly font types (for example, Coronet, Letter Gothic) which may not provide adequate contrast between text and the background (Saracevic \& Wood 198I; RNIB 2000). Too many font types in a single document can distract the reader. Betterley et al. (2000) therefore recommend use of no more than two simple typefaces in any one information material. 
Many agree that a 12-point typeface is adequate for most readers for information materials, such as PAIMs (Glanz \& Rudd 1990; NCl 1994; Anon. 2000). However, Payne et al. (2000) reported than less than half of patient information brochures in the United Kingdom met the minimum criterion of I2-pt font size recommended by RNIB (2000). Misanchuk (1989) studied the typographic preferences of learners and found that a Bookman 13-pt font was preferred above all other font type and size combinations. Betterley et al. (2000) suggest that font size can be reduced to II-pt to save space as long as leading text (headings) is large (12-pt) and prominent. Large fonts (14-16pt) might, however, be required for those with poor eyesight (RNIB 2000). Choice of font size is affected by the typeface chosen as typefaces vary in their apparent size at the same point size (Velasco et al. 1996).

\section{Highlighting}

Print style can be used to highlight certain information in a PAIM to draw the reader's attention to this information. Phrases or paragraphs can be underlined, rendered in bold or italics, written in upper case or in a different colour, presented within a box, or circled or marked by cues such as arrows and bullets (Misanchuk 1992; NCl 1994; Velasco et al. 1996; Betterley et al. 2000). To retain effectiveness attention-getting devices should not be overused ( $\mathrm{NCI}$ 1994). The use of capitals, in particular, should be restricted because long streams of text written in upper case are difficult to read (Velasco et al. 1996; Parker 1997; Anon. 2000). Variation in typography should not be used for its own sake or merely for aesthetic purposes (Velasco et al. 1996) but as a carefully applied tool to mark the essential parts of the message.

Saracevic and Wood (1981:214) use the term 'identifiability' to refer to signals other than words (written or spoken) and illustrations that help the cognition by drawing the attention of a reader (viewer, listener) to the key elements of content, major points made, summaries, changes in emphasis or topic, and so on. Consistent use of identifiers throughout the text (for example, consistent colour and font for headings) can serve as a mnemonic to aid the reader's recall of information through associations (Saracevic \& Wood 1981). Similarly, visual cues and graphics can be used at appropriate places in the document to enhance cognition and recall.

Using pictures and illustrations

Visuals (pictures, photos, graphs, diagrams) are commonly included in extension information materials and are thought to be especially important for a low-literacy audience who might struggle to understand the text without some explanatory pictures (Leichter et al. 198I; Bembridge 199I). Studies have confirmed the value of using pictures in instructional information materials (that is, materials that the reader is expected to read and understand without further verbal explanation). For example, Murphy et al. (1999) found that adding pictures designed to illustrate key points significantly enhanced comprehension and recall of information on HIV presented in brochures. Hoffmann (2000) also notes the potential pitfalls of miscommunication using pictures and suggests ways of using pictures together with text to overcome visual illiteracy.

Visual communication and the use of visual instructional materials, specifically visual materials as an adjunct to text, in adult education and health and agricultural extension is a complex but well-studied field (for example, Morgan 1986; Moore et al. 1990; Tufte 1990; Lester 1995; Lopes 1996) and is not reviewed here. Hoffmann (2000) provides comprehensive treatise of the potential and limitations of the use of pictures for communicating with a low-literacy audience in a rural setting.

\section{Conclusion}

Scientists and communication specialists should not regard repackaging as a menial and simple task, not worthy of their attention or inviting much reward, because producing perspicuous print materials requires a large measure of hard work and discernment. A collaborative approach, involving as far as possible members of the intended audience, to produce and more crucially evaluate PAIMs (Morris \& Stilwell in prep.), will probably achieve more than individual efforts (Salmon \& Myers 1999). Such endeavors can be inspired by the call of Joseph Pulitzer (of the Pulitzer Prize for Journalism) to:

Put it to them briefly so they will read it, clearly so they will appreciate it, picturesquely so they will remember it, and above all accurately so they will be guided by its light.

\section{Acknowledgements}

Three anonymous referees provided useful suggestions for improving the manuscript.

\section{References}

Aboyade, B.O. 1987. Library and information services to rural communities: RUDIS Project as a case study, in Libraries and literacy: proceedings of the seventh meeting of the Standing Conference of Eastern, Central and Southern African Librarians [SCECAL], Gaborone, 4-8 August 1986, together with reports on the SCECSAL/FID Pre-conference Workshop: Repackaging scientific and technical information for literate and/or semi literate users, Gaborone, 3I July - I August 1986, eds. Asamani, J.O., S.B. Monageng, G.K. Malindwa \& H.K. Raseroka. Gaborone: Botswana Library Association: $107-$ I I 4. 
Aina, L.O. 1990. Informing African farmers: some obstacles to information flow. Information development, 6(4): $201-203$.

Amaratunga, C. \& Shute, J. 1982. Extension and adult learning in a Ghanaian community. Canadian journal of African studies, I6: 549-566.

Anderson, M.L.F., Olson, C.M. \& Rhodes, K. 1980. Development and pilot testing of a tool for evaluating printed materials. Journal of nutrition education, I2(2): 50-54.

Anon. 2000. The art of communicating on paper. Spore, 86(April): 4-5.

Anyaegbunam, C., Mefalopulos, P. \& Moetsabi, T. I999. Participatory rural communication appraisal (PRCA) methodology. SD

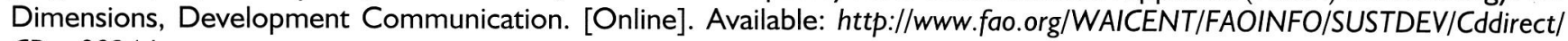
CDan0024.htm

Arthur,V.A.M. 1995. Written patient information: a review of the literature. Journal of advanced nursing, 21 : $108 \mathrm{I}-1086$.

Arunachalam, S. 1999. Information and knowledge in the age of electronic communication: a developing country perspective. Journal of information science, 465-476.

Avgerou, C. 2000. Recognising alternative rationalities in the deployment of information systems. Electronic journal on information systems in developing countries, 3(7): I-I5. [Online]. Available: http://www.is.cityu.edu.hk/Research/ejisdc/vol3/ v3r7.pdf

Ballantyne, P. 2002. Collecting and propagating local development content: synthesis and conclusions. [Online]. Available: $h t t p: /$ /www.ftpiicd.org/files/research/reports/report7.pdf

Behrens, J.H. \& Evans, J.F. 1984. Using mass media for extension teaching, in Agricultural extension: a reference manual, ed. B.E. Swanson. Rome: FAO: 144-I55.

Bembridge, T.J. I99I. Practical guidelines for agricultural extension workers: a field manual. Halfway House: Development Bank of South Africa.

Bembridge, T.J. 1995. Agricultural publications in information transfer. Report to the Directorate Information, National Department of Agriculture, Pretoria. (Unpublished).

Bembridge, T.J. 1997. Agricultural publications in small-scale farmer extension. South African journal of agricultural extension, 26: I-II.

Betterley, C. 2000. Guide to evaluating written nutrition education materials. Ames: lowa State University.

Betterley, C., Dobson, B. \& Ouverson, C. 2000. Written nutrition education materials review form. Ames: lowa State University.

Boag, A. ed. 1992. Designing business documents. Redhill: Monotype Typography.

Boone, K.M. 1996. Applying lessons from text research to extension education media. Journal of applied communications, 80: I9.

Burton, G.E. 199I. The readability of consumer-oriented bank brochures: an empirical investigation. Business and society, 30(I): $21-26$.

Burton, S. 200I. Development communication: towards a social action perspective, in Knowledge, information and development: an African perspective, eds. Stilwell, C., A. Leach \& S. Burton. Pietermaritzburg: School of Human and Social Studies, University of Natal: 218-233.

Carter, I. 1999. Locally generated printed materials in agriculture: experience from Uganda and Ghana. Education Research serial no 31 . London: Department for International Development.

Castells, M. 1996. The rise of the network society: the information age: economy, society and culture. Vol. I. Oxford: Blackwell.

Castells, M. 1999. The social implications of information and communication technologies, in World social science report, eds. Kazancigil, A. \& D. Makinson. New York: UNESCO.

Chung, V., Horowitz, A.M., Canto, M.T. \& Siriphant, P. 2000. Oral cancer educational materials for the general public. Journal of public health dentistry, 60(I): 49-52.

Coey, L. 1996. Readability of printed educational materials used to inform potential and actual ostomates. Journal of clinical nursing, 5(6): 359-366.

Cooper, K. 1994. Mind and matter. Communicators, 4(7): 9-II.

Correa, A.F., Ndiaye, D., Mchombu, K.J., Rodriguez, G.M., Rosenberg, D. \& Yapa, N.U. 1997. Rural information provision in developing countries: measuring performance and impact. UNESCO document no. Cll-97/WS/II. Paris: UNESCO.

Culbertson, V.L., Arthur, T.G., Rhodes, P.J. \& Rhodes, R.S. 1988. Consumer preference for verbal and written medication information. Drug intelligence and clinical pharmacy, 22: 390-396.

Dale, E. \& Chall, J. 1948. A formula for predicting readability. Educational research bulletin, 27: I -54.

Doak, L.G., Doak, C.C. \& Root, J.H. 1996. Teaching patients with low literacy skills. Second edition. New York: JB Lippincott.

Dollahite, J., Thompson, C. \& McNew, R. 1996. Readability of printed sources of diet and health information. Patient education and counseling, 27(2): 123-134.

Estey, A., Musseau, A. \& Keehn, L. 1994. Patients understanding of health information: a multihospital comparison. Patient education and counseling, 24(I): 73-78.

Flesch, R. 1948. A new readability yardstick. Journal of applied psychology, 32: 221-233.

Frost, M.H., Thompson, R. \& Thiemann, K.B. 1999. Importance of format and design in print patient information. Cancer practice, $7(\mathrm{I}): 22-27$.

Fry, E.B. 1968. A readability formula that saves time. Journal of reading, $11: 513-516$.

Glanz, K. \& Rudd, J. 1990. Readability and content analysis of print cholesterol education materials. Patient education and counseling, 16: 109-I 18.

Graber, M.A., Roller, C.M. \& Kaeble, B. 1999. Readability levels of patient education material on the World Wide Web. Journal of family practice, $48(1)$ : 58-6I.

Gunning, R. 1952. The technique for clear writing. New York: McGraw-Hill.

Hewins, E.T. 1990. Information needs and use studies, in Annual review of information science and technology, vol. 25, ed. Williams, ME. New York: American Society for Information Science/Elsevier: 95- 121. 
Hoffmann, V. 2000. Picture supported communication in Africa. Weikesheim: Margraf Verlag.

Jensen, M. 2002. The African Internet: a status report. [Online]. Available:

http://www3.wn.apc.org/africa/afstat.htm

Johnson, E.C. \& Verma, S. 1992. The readability of written mass mailing material produced th the county level of the Alabama Cooperative Extension Service. Journal of applied communications, 76: 49-57.

Kaniki, A.M. 200I. Community profiling and needs assessment, in Knowledge, information and development: an African perspective, eds. Stilwell, C., A. Leach \& S. Burton. Pietermaritzburg: School of Human and Social Studies, University of Natal: 187-20I.

Karlsson, J. 1995. Methods of information provision to rural communities in South Africa, in Proceedings of a seminar on Information Provision to Rural Communities in Africa, Gaborone, 22-25 June, 1994. Uppsala: Uppsala University Library: 47-57.

Kingbell, C. \& Speece, M.W. 1995. Readability of pediatric patient education materials. Clinical pediatrics, 34: 96-103.

Kiplangat, J. 200I. The role of telecentres in the provision of agricultural information for rural development in sub-Saharan Africa. Paper presented at the International Conference on Agricultural Information, Beijing, China. [Online]. Available: http://www.agrinfo200 I.org/06.htm

Kularatne, E.D.T. 1997. Information needs and information provision in developing countries. Information development, 13(3): $|17-| 2 \mid$.

Leach, A. 1999. The provision of information to adults in rural KwaZulu-Natal, South Africa, by non-governmental organisations. Libri, 49: 7I-89.

Leach, A. 200I. Information provision in a rural context: the perspectives of rural adults and some implications for rural library and information services. South African journal of library and information science, 67(2): 5 I-62.

Leichter, S.B., Nieman, J.A., Moore, R.W., Collins, P. \& Rhodes, A. 198I. Readability of self-care instructional pamphlets for diabetic patients. Diabetes care, 4(6): 627-630.

Lester, P.M. 1995. Visual communication: images with messages. Belmont: Wadsworth.

Liptak, C.S. 199I. Improving readability of extension materials. Journal of extension 29(4). [Online]. Available: $h t t p: / / w w w . j o e . o r g /$ joe//99/ winter/tt4.html

Lopes, D. 1996. Understanding pictures. London: Clarendon.

Lush, D. \& H. Rushwaya. eds. 2000. Into or out of the digital divide? Panos Southern Africa. [Online]. Available: http:// www. panos.org.zm/Contents.htm

Mansell, R. \& U. Wehn. eds. 1998. Knowledge societies: information technology for sustainable development. New York: Oxford University Press.

McLaughlin, H. 1969. Smog grading: a new readability formula. Journal of reading, 12: 639-646.

Meade, C.D. \& Smith, C.F. 199I. Readability formulas: cautions and criteria. Patient education and counseling, 17: I53- I58.

Melkote, S.R. 1991. Communication for development in the Third World. New Delhi: Sage.

Misanchuk, E.R. 1989. Learner preferences for typeface (font) and leading in print materials: technical report. Saskatoon: University of Saskatchewan.

Misanchuk, E.R. 1992. Preparing instructional text: document design using desktop publishing. Englewood Cliff: Educational Technology Publications.

Moore, M.B., Sørensen, M. \& Adebajo, C.F. 1990. Illustrated print materials for health and family planning education. World health forum, II: 302-307.

Morris, C.D. 2000. Bibliography of information materials for communal livestock farmers and research on communal areas in South Africa. BBibl Hons paper, Information Studies, University of Natal, Pietermaritzburg. [Online]. Available: http:// www.gssa.co.za/sacrb.html

Morris, C.D. \& Stilwell, C. in preparation. A review of procedures for evaluation print agricultural information materials.

Morgan, J. 1986. See what I mean: an introduction to visual communication. London: Edward Arnold.

Morton, J. \& Matthewman, R. 1996. Improving livestock products through extension: information needs, institutions and opportunities. Natural Resource Perspectives no. 12. London: Overseas Development Institute.

Munyua, H. 2000. Information and communication technologies (ICTs) for rural development and food security: lessons from field experiences in developing countries. Paper presented at a workshop on The Role of Information and Communication Technologies in Rural Development and Food Security, Rome, 5-6 June, 2000. [Online]. Available: http://www.fao.org/sd/ cddirect/CDre0055b.htm

Murphy, D.A., Okeefe, Z.H. \& Kaufman, A.H. 1999. Improving comprehension and recall of information for an HIV vaccine trial among women at risk for HIV: reading level simplification and inclusion of pictures to illustrate key concepts. AIDS education and prevention, II(5): 389-399.

$\mathrm{NCl}$. 1994. Clear and simple: developing effective print materials for low-literate readers. National Cancer Institute, United

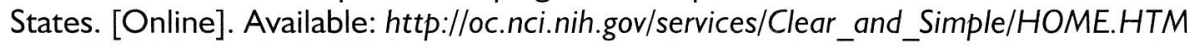

Nitzke, S. \& Voichick, J. 1992. Overview of reading and literacy research and applications in nutrition education. Journal of nutrition education, 24(5): 26I-266.

Orna, E. 1995. Information products in need of information management. Managing information, 2: 22-25.

Ozowa, V.N. 1995. Nature of agricultural information needs of small-scale farmers in Africa: the Nigerian example. Herald of library science, 34: 3-10.

Parker, R.C. 1997. Parker's one-minute designer. Revised edition. New York: IDG Books.

Payne, S., Large, S., Jarrett, N. \& Turner, P. 2000. Written information given to patients and families by palliative care units: a national survey. Lancet, 355: $1792-1795$.

Poole, H. 1985. Theories of the middle range. Norwood: Ablex, Norwood. 
Richardson, D. 1996. The Internet and rural development: recommendations for strategy and activity. Report prepared for the Food and Agriculture Organization of the United Nations, Rome. [Online]. Available: http://www.fao.org/WAICENT/ FAOINFO/SUSTDEV/CDdirect/CDDO/contents.html

RNIB. 2000. Clear print guidelines. Royal National Institute for the Blind. [Online]. Available: http://www.rnib.org.uk/wesupply/ fctsheet/clearp.htm

Rogers, E.M. 1983. Diffusion of innovations. Third edition. New York: Free Press.

Rosenberg, D. 1987. Repackaging scientific and technical information for illiterate and semi-literate users: a case study of the southern Sudan, in Libraries and literacy: proceedings of the seventh meeting of the Standing Conference of Eastern, Central and Southern African Librarians [SCECAL], Gaborone, 4-8 August 1986, together with reports on the SCECSAL/FID Preconference Workshop: Repackaging scientific and technical information for literate and/or semi literate users, Gaborone, 31 July - I August 1986, eds. Asamani, J.O., S.B. Monageng, G.K. Malindwa \& H.K. Raseroka. Gaborone: Botswana Library Association: 8-22.

Salinas, L.A. 1988. La comunicacion escrita en divulgaciones agricolas, in Fundamentos de communicacion cientifica y redaccion tecnica, ed. Molestina C. San Jose [Costa Rica]: IICA.

Salmon, T.P. \& Myers, C. 1999. Providing program review for cooperative extension publications. Journal of extension, 37(6).

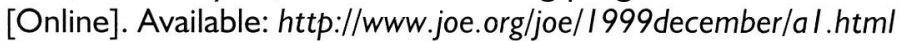

Saracevic, T. \& Wood, J.B. 198I. Consolidation of information: a handbook on evaluation, restructuring and repackaging of scientific and technical information. Pilot edition. Paris: UNESCO.

Shannon, C. \& Weaver, W.C. 1949. The mathematical theory of communication. Urbana: University of Illinois Press.

Singh, J. 1994. RAIN: readability assessment instrument manual. Midlothian: Woodlake Institute for Human Services.

Singh, J. 2000. The readability of HIV/AIDS education materials. AIDS education and prevention, 12(3): 2I 4-224.

Smith, S. 1998. Reviewer's checklist for health information materials. [Online]. Available: http://www.prenataled.com/pdf/ evaluate.pdf

Stewart, D. 1985. Let's hear it for print. Adult education, 58(2): I39-I47.

Stilwell, C. 200I. Repackaging information: a review, in Knowledge, information and development: an African perspective, eds. Stilwell, C., A. Leach \& S. Burton. Pietermaritzburg: School of Human and Social Studies, University of Natal: 4I-54.

Sturges, P. \& Chimseu, G. 1996. The chain of information provision in the villages of Malawi: a rapid rural appraisal. International information and library review, 28: 135-156.

Sturges, P. \& Neill, R. 1998. The quiet struggle: information and libraries for the people of Africa. Second edition. London: Mansell.

Tufte, E.R. 1990. Envisioning information. Cheshire: Graphics Press.

Turk, C. \& Kirkman, J. 1989. Effective writing: improving scientific, technical and business communication. London: Chapman and Hall.

Velasco, M.R., Kowalski, R. \& Lowe, J.C. 1996. Technology transfer materials: are we learning the technology of transfer? European journal of agricultural education and extension, 3: 35-46.

Youdeowei, A., Diallo, A. \& Spiff, E.D. 1995. Synthesis of regional studies of agricultural information needs of African countries, in The role of information for rural development in ACP countries: review and perspectives. Proceedings of an international seminar, Montpellier, France, 12-16 June, 1995: 113-138. 